\title{
Reassessment of the Goiânia radioactive waste repository in Brazil using HYDRUS-1D
}

\author{
Elizabeth M. Pontedeiro ${ }^{1,2 *}$, Paulo F. Heilbron ${ }^{3}$, Jesus Perez-Guerrero ${ }^{3}$, Jian $\mathrm{Su}^{1}$, \\ Martinus Th. van Genuchten ${ }^{2,4}$ \\ ${ }^{1}$ Department of Nuclear Engineering, Federal University of Rio de Janeiro, UFRJ, Rio de Janeiro, RJ, Brazil. \\ ${ }^{2}$ Department of Earth Sciences, Utrecht University, Utrecht, Netherlands. \\ ${ }^{3}$ Brazilian Nuclear Energy Commission, CNEN, Rio de Janeiro, RJ, Brazil. \\ ${ }^{4}$ Center for Environmental Studies, CEA, São Paulo State University, UNESP, Rio Claro, SP, Brazil. \\ *Corresponding author. E-mail: bettinadulley@hotmail.com
}

\begin{abstract}
In September 1987 an accident occurred with a cesium chloride $(\mathrm{CsCl})$ teletherapy source taken from a cancer therapy institute in Goiânia, Brazil. Misuse of the abandoned source caused widespread contamination of radioactive material (about $50 \mathrm{TBq}$ of ${ }^{137} \mathrm{Cs}$ ) in the town of Goiânia. Decontamination of affected areas did lead to about $3,500 \mathrm{~m}^{3}$ of solid radioactive wastes, which were disposed in two near-surface repositories built in concrete in 1995 . This paper documents a safety assessment of one of the low-level radioactive waste deposits containing ${ }^{137} \mathrm{Cs}$ over a time period of 600 years. Using HYDRUS-1D, we first obtained estimates of water infiltrating through the soil cover on top of the repository into and through the waste and its concrete liners and the underlying vadose zone towards groundwater. Calculations accounted for local precipitation and evapotranspiration rates, including root water uptake by the grass cover, as well as for the effects of concrete degradation on the hydraulic properties of the concrete liners. We next simulated long-term water fluxes and ${ }^{137} \mathrm{Cs}$ transport from the repository towards groundwater. Simulations accounted for the effects of ${ }^{137} \mathrm{Cs}$ sorption and radioactive decay on radionuclide transport from the waste to groundwater, thus permitting an evaluation of potential consequences to the environment and long-term exposure to the public. Consistent with previous assessments, our calculations indicate that very little if any radioactive material will reach the water table during the lifespan of the repository, also when accounting for preferential flow through the waste.
\end{abstract}

Keywords: Cs-137 transport; Goiânia radioactive waste repository; HYDRUS-1D; Safety assessment.

\section{INTRODUCTION}

In September 1987 a major accident occurred with an old Cesium teletherapy source taken from an abandoned cancer therapy institute (Instituto Goiano de Radioterapia) in the Brazilian town of Goiânia. Misuse of the source caused widespread contamination of radioactive material (about $1375 \mathrm{Ci}$ of ${ }^{137} \mathrm{Cs}$, or $5 \times 10^{13} \mathrm{~Bq}$ ), leading to four deaths and about 250 people showing significant levels of internal or external contamination (Heilbron et al., 2002; IAEA, 1988; Paschoa et al., 1993; Roberts, 1987). Subsequent cleanup of ${ }^{137} \mathrm{Cs}$ contaminated areas generated about $3,500 \mathrm{~m}^{3}$ of solid radioactive waste totaling some 6,000 tons of material. The waste was disposed in two near-surface low-level radioactive waste repositories built in reinforced concrete. Previously, two safety assessments were carried out, in 1995 and 2002, to evaluate the performance of the repositories over a 400-year time period (Heilbron et al., 2002). The studies were mandated by the Brazilian Nuclear Regulatory Agency (CNEN) as part of their regular assessments of the long-term effects of the Goiânia waste repositories on the environment and human health.

Numerical models have long been recognized to be important tools for radioactive waste repository design, operation and environmental regulation (e.g., Pontedeiro et al., 2010; Robinson et al., 2012; Tsang (Ed.), 1987). They are important to understand the long-term subsurface fate and transport of contaminants leached from solid waste disposal sites as a function of climatologic conditions, local hydrogeologic conditions, and repository design. Performance assessments are especially important to evaluate the future safety of installations containing radioactive materials with long-lived radionuclides. This may need to include evaluations of how gradual processes of degradation of engineered and natural barriers of the repositories after their closure would affect the environment (Jacques et al., 2013, 2014; Pabalan et al., 2009). Other events or processes could also compromise the integrity of a repository, such as intrusion by humans and animals (Naveira-Cotta et al., 2013; Yu et al., 2007).

The current study was carried out to provide a mandatory five-year reassessment of the possible future impacts of the Goiânia radioactive waste repositories on the environment and biosphere, as requested by the Brazilian Nuclear Regulatory Agency. While many models potentially could be used for such an analysis (e.g., as inventoried by Mallants et al., 2011), we used in our study the HYDRUS-1D software of Šimůnek et al. (2016). Below we first give a brief description of the Goiânia waste disposal site, including a synopsis of previous assessments, then discuss HYDRUS-1D as used to evaluate ${ }^{137} \mathrm{Cs}$ transport from the waste site to the underlying vadose zone and groundwater, and provide results of the calculations.

\section{THE GOIÂNIA RADIOACTIVE WASTE REPOSITORY}

To facilitate the safe disposal of radioactive waste generated during decontamination in Goiânia, two near-surface repositories were constructed. The first one was a near-surface repository for disposal of very low-activity wastes $(40 \%$ in volume, with specific ${ }^{137} \mathrm{Cs}$ activities less than $87 \mathrm{~Bq} / \mathrm{g}$ ), while the second repository (also a near-surface type) was constructed for higher-activity wastes $(60 \%$ in volume, with specific activities above $87 \mathrm{~Bq} / \mathrm{g}$ ). This second repository, being the focus of this study, was built in concrete, having dimensions of $19.6 \mathrm{~m}$ 


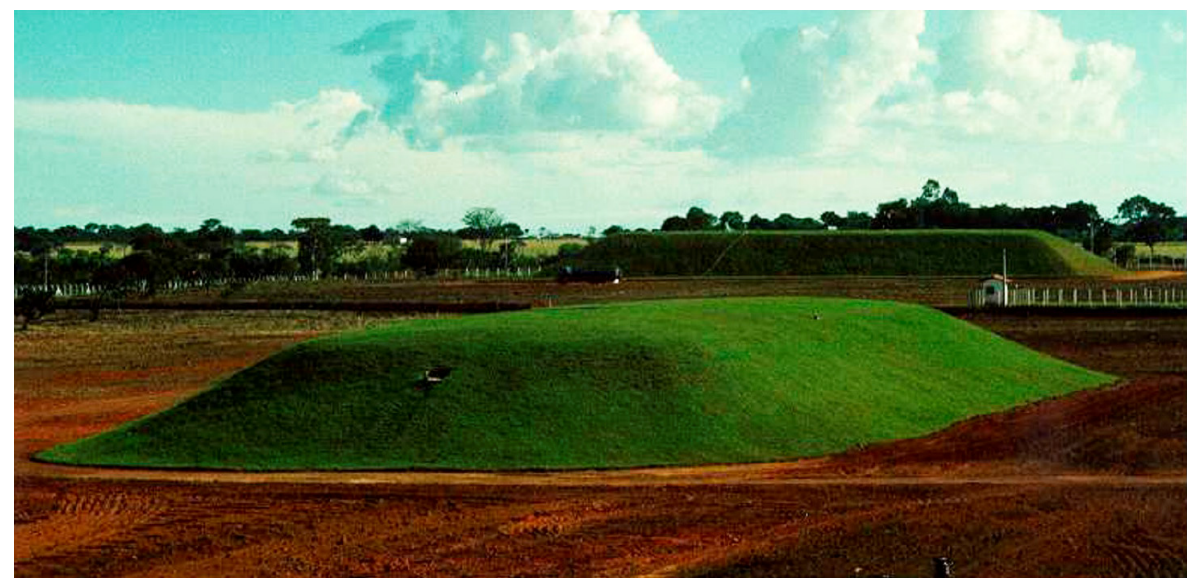

Fig. 1. View of the Goiânia near-surface repositories. The repository in the front contains relatively low-activity ${ }^{137} \mathrm{Cs}$ waste (specific activities less than $87 \mathrm{~Bq} / \mathrm{g}$ ), and the repository in the back higher-activity waste (specific activities above $87 \mathrm{~Bq} / \mathrm{g}$ ).

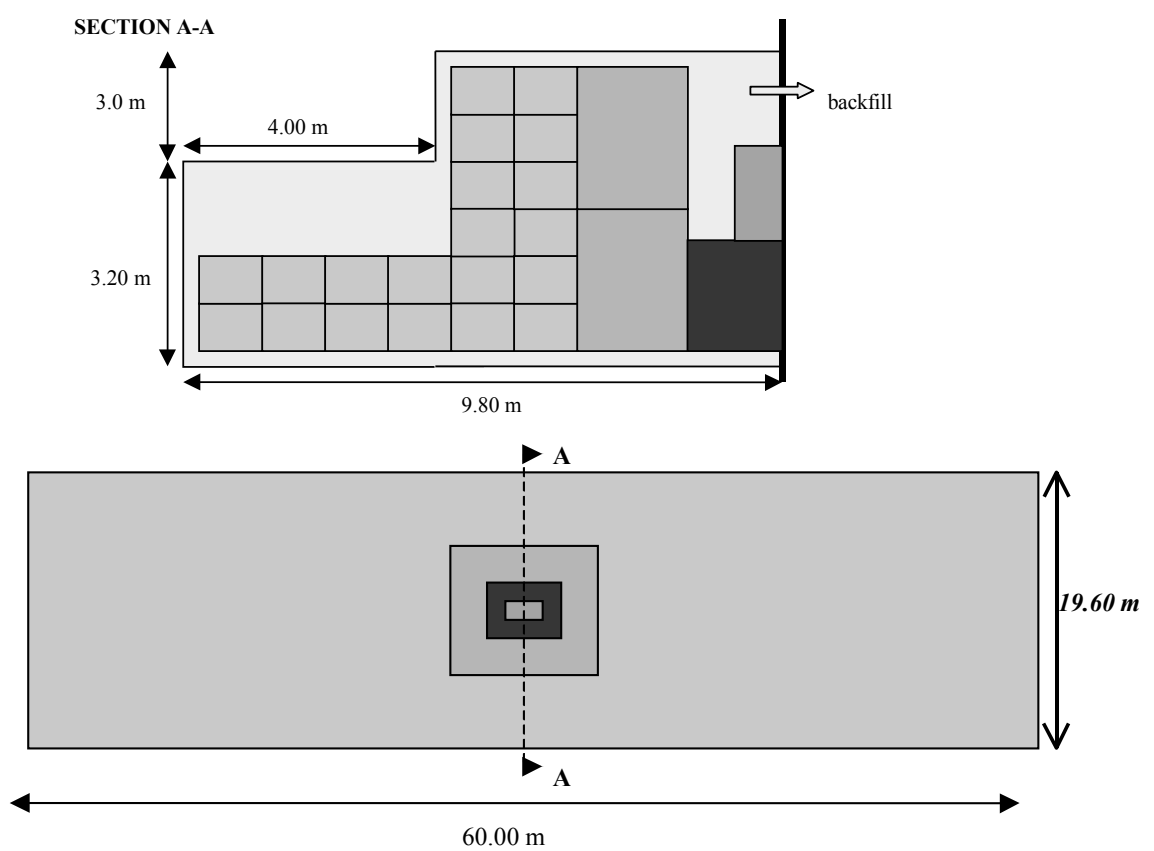

Fig. 2. Schematic internal cross-section (a) and areal view (b) of the Goiânia near-surface higher-activity radioactive waste repository (Heilbron et al., 2002).

length, $60 \mathrm{~m}$ width and $6.20 \mathrm{~m}$ height, and with $20-\mathrm{cm}$ thick concrete walls along all sides of the facility, including the top and bottom. A $50-\mathrm{cm}$ thick uniform soil cover was placed on top of the repository and vegetated with grass. Figure 1 gives an above-ground view of the two constructed repositories.

Waste inside the second repository considered here consisted mostly of compacted soil contaminated with ${ }^{137} \mathrm{Cs}$, covering a height of about $4.38 \mathrm{~m}$. A schematic of the design of the facility is shown in Figure 2. The concrete deposit contained inside various types of containers filled with waste having diverse activity levels. Void spaces between the containers were filled and compacted with natural material, composed of sand and clay. While macroscopically quite heterogeneous, for the purpose of this study we considered the resulting waste material to be distributed in a homogeneous manner, with the hydraulic characteristics of the waste being the same as those of the compacted soil. The repository is located at $16^{\circ} 45^{\prime} 32^{\prime \prime} \mathrm{S}, 49^{\circ} 26^{\prime} 16^{\prime \prime}$ $\mathrm{W}$, about $770 \mathrm{~m}$ above sea level. Depth to groundwater below the lower concrete liner during the year fluctuated between 4 and 5 $\mathrm{m}$, with $4.5 \mathrm{~m}$ being a good average value.

\section{PREVIOUS ASSESSMENTS}

In 1995 the first environmental safety assessment of the Goiânia radioactive waste disposal site was conducted by the Brazilian Nuclear Energy Commission (CNEN) using a screening model (Heilbron et al., 1995, 1996). The assessment considered one of the main scenarios of the possible impact of the repository to be the water pathway, mostly involving the ingestion of water or vegetable and animal products contaminated by irrigation water from a nearby contaminated well. Also considered was an agricultural pathway in which an inadvertent intruder mixes contaminated soil with native garden soil, as well as a scenario where the intruder during digging encounters an intact engineered barrier that is not further penetrated. Another conservative scenario considered rapid natural degradation of 
the repository cap until complete failure after only 30 years, at which time the contaminant is allowed to move freely to the water table and then to migrate laterally by groundwater to a well only $2 \mathrm{~m}$ downgradient. This last scenario, which allowed water from the well to be used in a vegetable garden, resulted in a transit time for ${ }^{137} \mathrm{Cs}$ through the 4 to $5 \mathrm{~m}$ thick unsaturated zone of at least 423 years, and concentrations that produced potential doses that remained always below the lower limit of $0.25 \mathrm{mSv}$ allowed by CNEN. Since the calculated maximum concentrations in groundwater below the repository always remained below the allowed concentrations at any time, the groundwater pathway was not considered important.

A reassessment of the Goiânia repository was carried out in 2002 using a hybrid numerical-analytical approach based on the standard advection-dispersion equation assuming steady-state downward flow through the repository, with the contaminant subject to equilibrium sorption and radioactive decay, and with a certain fraction of the waste being stable and not subject to leaching (Heilbron et al., 2002). The 2002 reassessment confirmed the 1995 results in that the ${ }^{137} \mathrm{Cs}$ water pathways related to a possible residential scenario near the site were found to be negligible, mostly again because of the long residence time in the unsaturated zone below the repository, which hence served as a natural barrier. The maximum ${ }^{137} \mathrm{Cs}$ concentration at any time below the repository was again found to be below the maximum value of $25,000 \mathrm{~Bq} / \mathrm{m}^{3}$ (about $6.8 \times 10^{-7} \mathrm{Ci} / \mathrm{m}^{3}$ ), which would result in a dose for an individual of $0.25 \mathrm{mSv} / \mathrm{y}$. The 2002 reassessment also found that of the three intrusion scenarios considered in 1995, the potentially most hazardous case would be the agriculture scenario. But since this would occur only after the assumed complete degradation of the concrete (300 to 500 years), the results would still not be important since after 280 years the doses would be lower than the allowed limit of $1 \mathrm{~m} \mathrm{~Sv} / \mathrm{y}$ due to natural decay of ${ }^{137} \mathrm{Cs}$. If one were to neglect this possibility (i.e., degradation of concrete during a period of time less than 300 years), the most important scenario would be the post-drilling scenario after an institutional control period of 50 years. The calculations were consistent with a 7year environment monitoring plan (EMP) of the site, which showed that it was very unlikely to find in the future dangerous concentrations of ${ }^{137} \mathrm{Cs}$ in the aquifer for population living near the site. All concentrations were found to be below the detection limit of $200 \mathrm{~Bq} / \mathrm{m}^{3}$ (about $5.4 \times 10^{-9} \mathrm{Ci} / \mathrm{m}^{3}$ ).

In this paper we provide another reassessment, as mandated by CNEN, in which HYDRUS-1D is used to follow ${ }^{137} \mathrm{Cs}$ transport from the repository through the unsaturated zone to underlying groundwater. An important part of the current study is an assessment of the possible effects of degradation of the concrete cap on transient infiltration into and through the repository. Modeling of fluid flow through the entire repository assembly was done in two steps. The first step focused on fluid flow through the cover over a period of 600 years, rather than only 400 years as in the first two assessments, as well as partial degradation of the upper concrete liner covering the waste. In a second step, water flow and ${ }^{137} \mathrm{Cs}$ transport through the waste, the lower concrete liner and the vadose zone was followed using the infiltration rates obtained from the first step. We also briefly considered the effects of possible preferential flow through the waste.

\section{SIMULATION METHODOLOGY}

Simulations using HYDRUS-1D assumed applicability of the Richards equation for flow in variably-saturated media as follows:

$$
\frac{\partial \theta(h)}{\partial t}=\frac{\partial}{\partial z}\left[K(h)\left(\frac{\partial h}{\partial z}-1\right)\right]-S(h)
$$

where $\theta$ is the volumetric water content, $h$ is the pressure head, $K$ is the unsaturated hydraulic conductivity, $S(h)$ is a water sink term (in our study associated with root water uptake), $z$ is the vertical coordinate (positive downwards), and $t$ is time. The soil hydraulic functions $\theta(h)$ and $K(h)$ in Eq. (1) were described using the original constitutive relationships of van Genuchten (1980):

$$
\begin{aligned}
& S_{e}(h)=\frac{\theta(h)-\theta_{r}}{\theta_{s}-\theta_{r}}=\left(1+|\alpha h|^{n}\right)^{-m} \quad(m=1-1 / n) \\
& K(h)=K_{s} S_{e}^{0.5}\left[1-\left(1-S_{e}^{1 / m}\right)^{m}\right]^{2}
\end{aligned}
$$

where $S_{e}$ is effective saturation, $\theta_{r}$ and $\theta_{s}$ are the residual and saturated water contents, respectively, $K_{s}$ is the saturated hydraulic conductivity, and $\alpha$ and $n$ are quasi-empirical shape parameters.

The root water uptake term $S(h)$ in Eq. (1) was described with the equation (Feddes et al., 1978)

$$
S(h)=\alpha_{w}(h) \beta(z) T_{p}
$$

in which $\alpha_{w}(h)$ is the water stress response function $(0 \leq \alpha \leq 1)$, $\beta(z)$ represents the normalized root density distribution in the profile, and $T_{p}$ is the potential transpiration rate. For $\alpha_{w}(h)$ we used the piecewise linear reduction function by Feddes et al. (1978) using the default parameter values of grass as embedded within HYDRUS-1D.

Transport of the Cs radionuclide was modeled at first using the equilibrium advection-dispersion equation accounting for decay in both the liquid and solid phases:

$$
\frac{\partial(\theta R C)}{\partial t}=\frac{\partial}{\partial z}\left(\theta D \frac{\partial C}{\partial z}\right)-\frac{\partial q C}{\partial z}-\mu R C
$$

where $C$ is the solution concentration, $R$ is the solute retardation factor, $D$ is the solute dispersion coefficient, $q$ is the volumetric fluid flux, and $\mu$ is the radionuclide decay rate coefficient. The retardation factor $R$ for linear equilibrium sorption is given by

$$
R=1+\frac{\rho K_{d}}{\theta}
$$

in which $\rho$ is the dry soil bulk density and $K_{d}$ the distribution coefficient of ${ }^{137} \mathrm{Cs}$ between the liquid and solid phases. For the dispersion coefficient $D$ we used the standard equation

$$
D=D_{o} \tau+\lambda\left|\frac{q}{\theta}\right|
$$

in which $D_{o}$ is the diffusion coefficient of ${ }^{137} \mathrm{Cs}$ in water, $\tau$ is the tortuosity factor described here as a function of the water content using the equation of Millington and Quirk (1961), and $\lambda$ the dispersivity.

Tables 1 and 2 summarize the main soil physical and chemical parameters, respectively, used in the simulations. For the soil cover we used soil hydraulic parameters from a typical Cerrado soil in the Goiânia area of Brazil (Batalha et al., 2010) containing $53 \%$ of sand, $10 \%$ of silt and $37 \%$ clay. The initial 
Table 1. Soil physical properties of the repository system used in the simulations.

\begin{tabular}{|l|c|c|c|c|c|c|}
\hline Layer & $\begin{array}{c}\text { Depth } \\
(\mathrm{m})\end{array}$ & $\begin{array}{c}\theta_{r} \\
\left(\mathrm{~cm}^{3} \mathrm{~cm}^{-3}\right)\end{array}$ & $\begin{array}{c}\theta_{s} \\
\left(\mathrm{~cm}^{3} \mathrm{~cm}^{-3}\right)\end{array}$ & $\begin{array}{c}\alpha \\
\left(\mathrm{cm}^{-1}\right)\end{array}$ & $\begin{array}{c}n \\
(-)\end{array}$ & $\begin{array}{c}K_{s} \\
\left(\mathrm{~cm} \mathrm{day}^{-1}\right)\end{array}$ \\
\hline \hline Top soil & $0-0.50$ & 0.067 & 0.386 & 0.0267 & 1.31 & 13.2 \\
\hline Upper concrete liner & $0.50-0.70$ & 0.000 & 0.204 & 0.00142 & 1.52 & $0.000864^{*}$ \\
\hline Waste layer & $0.70-5.08$ & 0.070 & 0.365 & 0.0281 & 1.18 & 5.99 \\
\hline Lower concrete liner & $5.08-5.28$ & 0.000 & 0.306 & 0.00142 & 1.52 & 0.0864 \\
\hline Vadose zone & $5.28-10.28$ & 0.078 & 0.409 & 0.0232 & 1.29 & 7.47 \\
\hline
\end{tabular}

*Initial value before degradation

Table 2. Soil chemical properties of the repository system used in the simulations.

\begin{tabular}{|l|c|c|c|c|c|c|}
\hline Layer & $\begin{array}{c}\text { Depth below upper } \\
\text { concrete liner (m) }\end{array}$ & $\begin{array}{c}D_{o} \\
\left(\mathrm{~cm}^{2} \mathrm{day}^{-1}\right)\end{array}$ & $\begin{array}{c}\rho_{b} \\
\left(\mathrm{~cm}^{3} \mathrm{~g}^{-1}\right)\end{array}$ & $\begin{array}{c}\lambda \\
(\mathrm{cm})\end{array}$ & $\begin{array}{c}K_{d} \\
\left(\mathrm{~cm}^{3} \mathrm{~g}^{-1}\right)\end{array}$ & $\begin{array}{c}\mu_{w,} \mu_{s} \\
\left(\mathrm{day}^{-1}\right)\end{array}$ \\
\hline \hline Waste layer & $0-4.38$ & 1.0 & 1.72 & 25.0 & 463 & $6.33 \times 10^{-5}$ \\
\hline Lower concrete liner & $4.38-4.58$ & 1.0 & 1.60 & 25.0 & 10.0 & $6.33 \times 10^{-5}$ \\
\hline Vadose zone & $4.58-9.58$ & 1.0 & 1.30 & 25.0 & 430 & $6.33 \times 10^{-5}$ \\
\hline
\end{tabular}

hydraulic parameters for the upper reinforced concrete liner were taken from literature values, mostly those by Schneider et al. (2012). We assumed that degradation of the concrete occurred slowly but steadily, starting after 10 years of operation of the repository. The main effect of concrete degradation, in terms of the long-term flow rates through the repository system and underlying vadose zone, is the change in the saturated hydraulic conductivity, $K_{s}$, of the liner. We assumed that after 10 years of operation, $K_{s}$ would increase slowly but continuously in a logarithm manner from the initial value of $10^{-10} \mathrm{~m} / \mathrm{s}(0.000864 \mathrm{~cm} /$ day, or $0.315 \mathrm{~cm} /$ year $)$ after 10 years to $10^{-9} \mathrm{~m} / \mathrm{s}$ after 225 years and $10^{-8} \mathrm{~m} / \mathrm{s}$ after 400 years, to approximately the same value as for the waste.

The contaminated waste layer in the repository was taken to be $4.38 \mathrm{~m}$ thick, situated over a $20-\mathrm{cm}$ thick concrete liner and a 5-m thick vadose zone to the average water table. Hydraulic properties of the waste layer were measured (Pereira, 1996), including the bulk density (average value of $1.70 \mathrm{~g} / \mathrm{cm}^{3}$ ) and a value of $463 \mathrm{~cm}^{3} / \mathrm{g}$ for the $K_{d}$ of that layer. The relatively high bulk density of the waste reflected compaction of the ${ }^{137} \mathrm{Cs}$ contaminated soils. The concrete liner below the waste was assumed to have the same unsaturated hydraulic properties as the degraded upper concrete liner, except for a slightly higher porosity and higher conductivity. Our reasoning here was that the flow rate into and through the repository was controlled mostly only by the very low fluid flow rate through the upper liner into the waste, with the conductivity of the lower liner not having not much of an effect anymore so that a constant value could be uses (equal to $K_{s}$ of the upper liner after degradation). We further used a partitioning coefficient $\left(K_{d}\right)$ of $10 \mathrm{~cm}^{3} / \mathrm{g}$ for the concrete (Aguiar, 2006). Hydraulic properties and $K_{d}$ of the vadose zone were measured (Pereira, 1996), with a bulk density of $1.30 \mathrm{~g} / \mathrm{cm}^{3}$ and a mean value of $430 \mathrm{~cm}^{3} / \mathrm{g}$ for the distribution coefficient, $K_{d}$.

Potential evapotranspiration $\left(E_{p}\right)$ rates needed for the simulations were obtained with the equation of Hargreaves (1975) using 10 years of temperature and precipitation data from a local weather station. Results are shown in Figure 3. The $E_{p}$ data were repeated several times as needed for longer-term calculations.

\section{WATER FLOW SIMULATIONS}

Modeling of the repository was done in two steps (Fig. 4). First flow rates through the tops soil cover and upper concrete

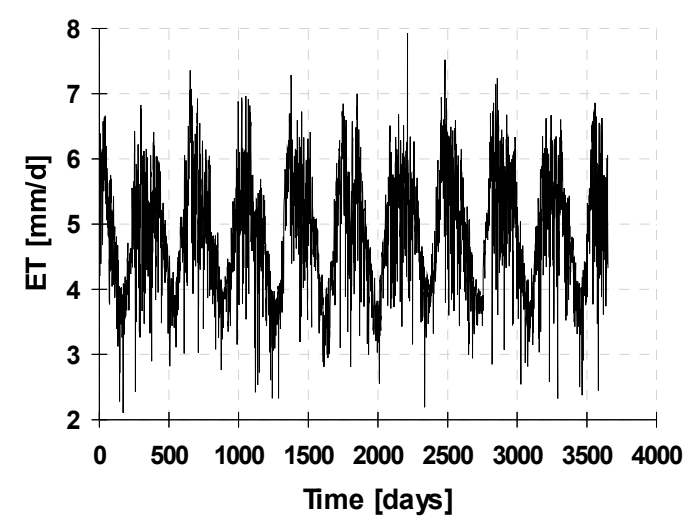

Fig. 3. Calculated potential evapotranspiration $\left(E_{p}\right)$ rates during a ten-year time period at Goiânia.

liner into the repository were studied, assuming some degradation of the concrete liner, during a time period of 600 years. Fluxes through the upper liner into the repository obtained in this manner were used next to estimate ${ }^{137} \mathrm{Cs}$ transport rates from the waste vertically down towards the water table.

A major challenge was to accurately estimate downward infiltration rates into the waste through the $70-\mathrm{cm}$ cap of the repository, i.e., $50 \mathrm{~cm}$ topsoil covered by grass and the upper concrete liner that presumably undergoes decay. Degradation of the concrete would have mostly an effect on the saturated hydraulic conductivity $\left(K_{s}\right)$, with the effects on porosity (or $\theta_{s}$ ) and the other hydraulic parameters (notably $\theta_{r}, \alpha$ and $n$ ) being far less important in terms of affecting fluid flow rates through the repository. Figure 5 shows how the $K_{s}$ value of the upper concrete liner affected infiltration rates into the waste. Infiltration rates up to about $15 \mathrm{~cm} /$ year were determined nearly exclusively by the permeability of the liner, while at higher $K_{s}$ values the local atmospheric conditions and moisture dynamics in the top soil determined the infiltration rate. The final asymptotic value for the flow rate was about $65 \mathrm{~cm} /$ year when the conductivity of the upper liner approached the value of the waste after 400 years (not further shown in Fig. 5).

The calculations for Fig. 5 were carried out using a seepage face as the lower boundary of the cap, thus assuming limited direct capillary contact between the waste and the upper liner. The seepage face boundary at the bottom of the concrete liner was set at zero pressure head, which hence allowed water 


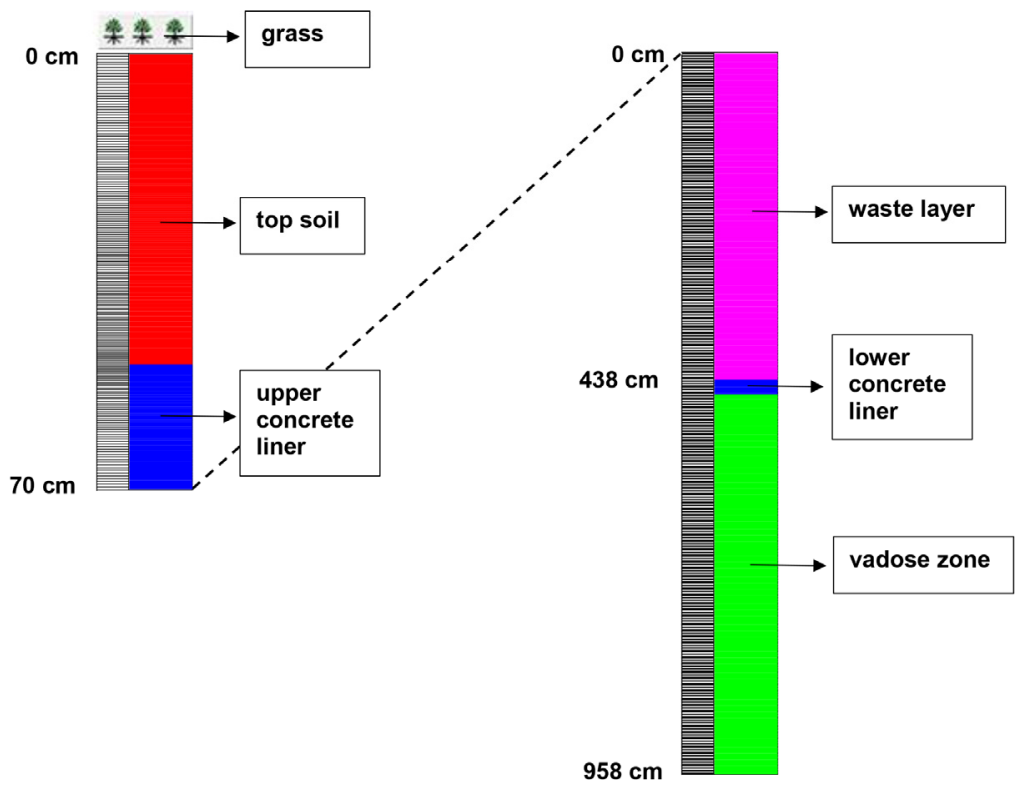

Fig. 4. Assumed profiles for simulations of flow through the soil cover and upper concrete liner (left plot), and of flow and Cs transport through the waste and underlying vadose zone (right plot), including the adopted finite element discretizations (please note that the left and right plot have different spatial scales).

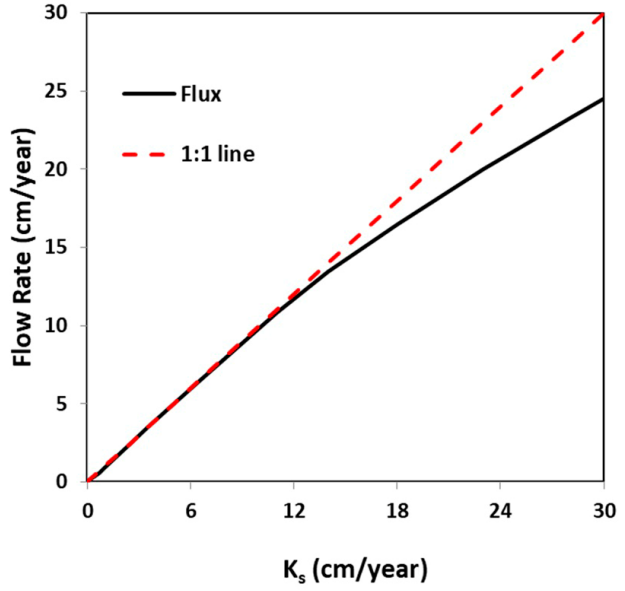

Fig. 5. Effect of the saturated hydraulic conductivity $\left(K_{s}\right)$ of the upper concrete liner on the rate of infiltration into the waste.

to slowly move (drip) from the liner into the waste (or allowing water to evaporate from the liner). Using boundary pressure head values of -10 or $-60 \mathrm{~cm}$ for the seepage face did not have much effect on the infiltration rates, as did not any changes in the values of $\theta_{r}, \theta_{s}, \alpha$ and $n$, generally leading to only a few percentages higher (notably with higher $\theta_{s}$ values) or lower (with higher $\alpha$ values) flow rates. The results in Figure 4 were obtained with a root distribution that declined linearly from the soil surface to zero at the soil-liner interface at a depth of 50 . Changing the root distribution to only the upper $30 \mathrm{~cm}$ also did not materially affect the comparison between $K_{s}$ and net infiltration, except for very small increases in the extremely low rates (those less than about $1 \mathrm{~cm} /$ year in Fig. 5).

Once the results in Fig. 5 were established, we calculated the flow regime through the waste, the lower concrete liner and the underlying vadose zone. Figure 6 shows the simulated pressure head and water content distributions during the assumed 600year life span of the repository. As initial condition for the pressure head we used the steady-state profile calculated with an upper boundary flux approximately equal to the saturated hydraulic conductivity $\left(K_{s}\right)$ of the upper liner before degradation, consistent with Fig. 4. Figure 6 shows that, as the upper liner slowly degraded, more moisture would enter the repository and increase the water contents and fluid flow rates.

\section{CESIUM TRANSPORT SIMULATIONS}

Estimated infiltration rates into the repository were used next for the ${ }^{137} \mathrm{Cs}$ transport calculations. Figure 7 shows calculated ${ }^{137} \mathrm{Cs}$ concentrations of fluid leaving the waste and the lower concrete liner into the underlying vadose zone. Notice that the concentrations are already very much lower than those in the waste layer, mostly because of the very low fluid flow rates and the relatively high $K_{d}$ value $\left(463 \mathrm{~cm}^{3} / \mathrm{g}\right)$ for ${ }^{137} \mathrm{Cs}$ in the waste. Figure 8 further shows the Cesium distributions at three locations below the lower concrete liner, i.e., at locations $\mathrm{N} 1(12 \mathrm{~cm}), \mathrm{N} 2(23 \mathrm{~cm})$ and N3 $(34 \mathrm{~cm})$ below the liner. Notice that concentrations considerable decreased in time because of slow movement and radioactive decay. ${ }^{137} \mathrm{Cs}$ concentrations eventually approach zero because of the decay.

For completeness we also present, in Fig. 9 on a semi-log scale, the entire ${ }^{137} \mathrm{Cs}$ concentration profiles in the waste and underlying vadose zone. Notice again the slowly moving concentration front due to the high $K_{d}$ value of the soil below the repository (Table 2), with the retardation factor being about 1530 , as well as rapidly decreasing concentrations due to radioactive decay. Radionuclides hence remained restricted nearly entirely to the upper $50 \mathrm{~cm}$ of the vadose zone. These results suggest that very little if any radioactive material will reach the water table during the life span of the repository.

All of the calculations thus far assumed applicability of the standard Richards equation for flow in variably-saturated media, the equilibrium advection-dispersion equation for Cesium transport, and the presence of slowly degrading concrete liners.

These relatively ideal conditions may not necessarily be met in practice. For this reason we also considered two scenarios that would alter the above standard approach: More rapidly degrading concrete liners, and preferential flow through the waste layer and underlying vadose zone. 

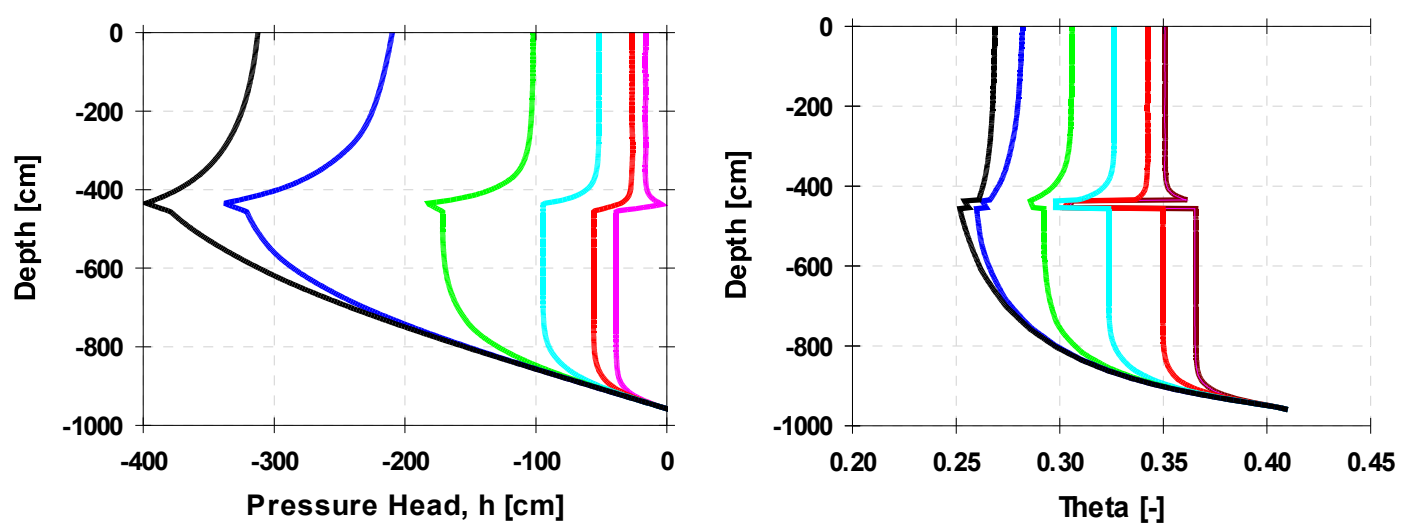

Fig. 6. Calculated pressure head and water content distributions in the repository (below the upper concrete liner) and underlying vadose zone. Distributions are given at every 100 years from left $(t=0$, representing the initial conditions) to right $(t=600$ years). The distributions after 500 and 600 years on the right were essentially identical.

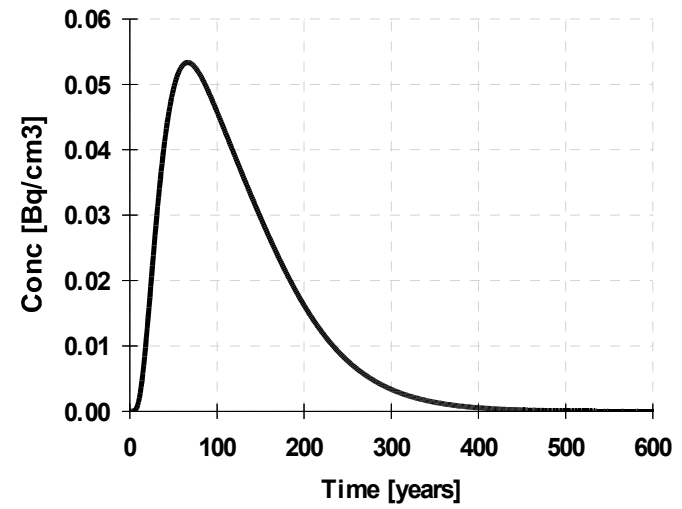

Fig. 7. Calculated ${ }^{137} \mathrm{Cs}$ concentrations just below the lower concrete liner at the bottom of the waste layer.

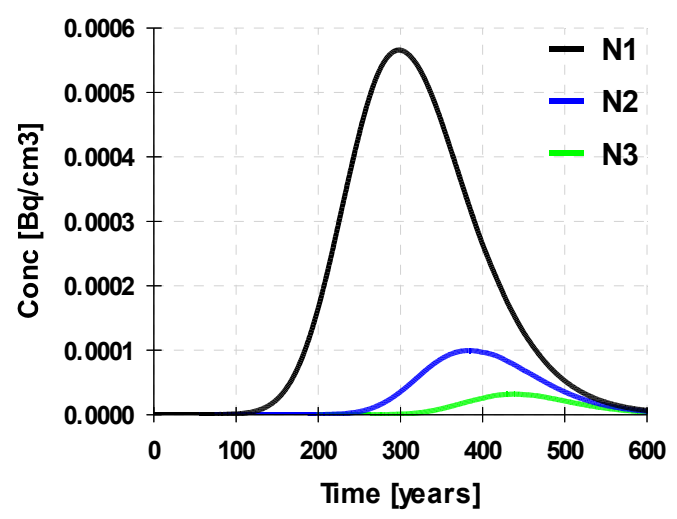

Fig. 8. Calculated ${ }^{137} \mathrm{Cs}$ concentrations in the vadose zone 12,23 and $34 \mathrm{~cm}$ below the lower concrete liner of the Goiânia repository.

For the first scenario we assumed that the concrete liners completely failed after installation, possible due to the development of cracks and/or dissolution or other alterations of the upper liner due to repeated wetting and drying cycles and perhaps the effect of plant roots. We used for these calculations a net infiltration rate of $65 \mathrm{~cm} /$ year $(0.187 \mathrm{~cm} /$ day $)$, which we obtained for the case when the saturated hydraulic conductivity $\left(K_{s}\right)$ of the upper liner would not limit the long-term downward infiltration rate as derived from the atmospheric boundary con-

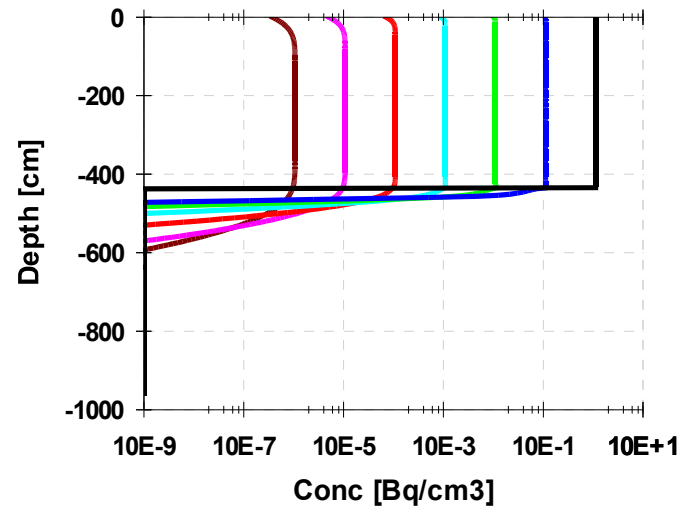

Fig. 9. Calculated ${ }^{137} \mathrm{Cs}$ concentration within the waste, the lower concrete liner and underlying vadose zone. Distributions are given every 100 years from right $(t=0$, representing the initial condition) to left ( $t=600$ years).

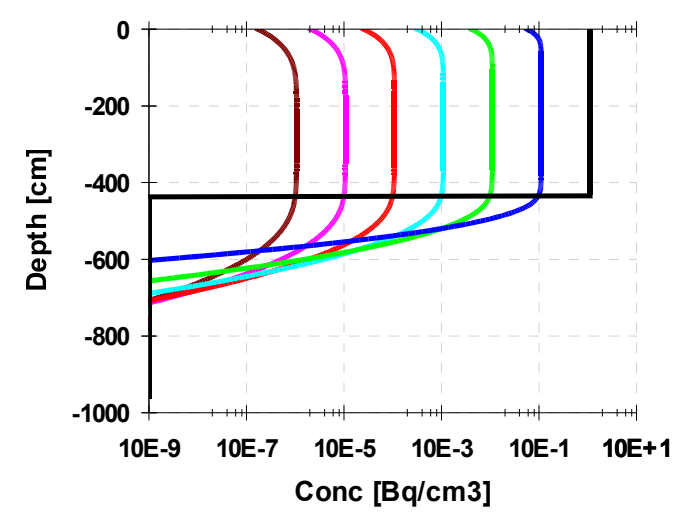

Fig. 10. Calculated ${ }^{137} \mathrm{Cs}$ concentration at three locations in the vadose zone below the lower concrete liner. Distributions are given every 100 years from right $(t=0$, representing the initial condition) to left ( $t=600$ years).

ditions (Fig. 3). Figure 10 shows the resulting ${ }^{137}$ Cs distribution in the profile below the upper concrete liner. The calculations indicate that the concentration front now moves slightly deeper into the vadose zone, but still not to depths and at concentrations that should be a concern. 

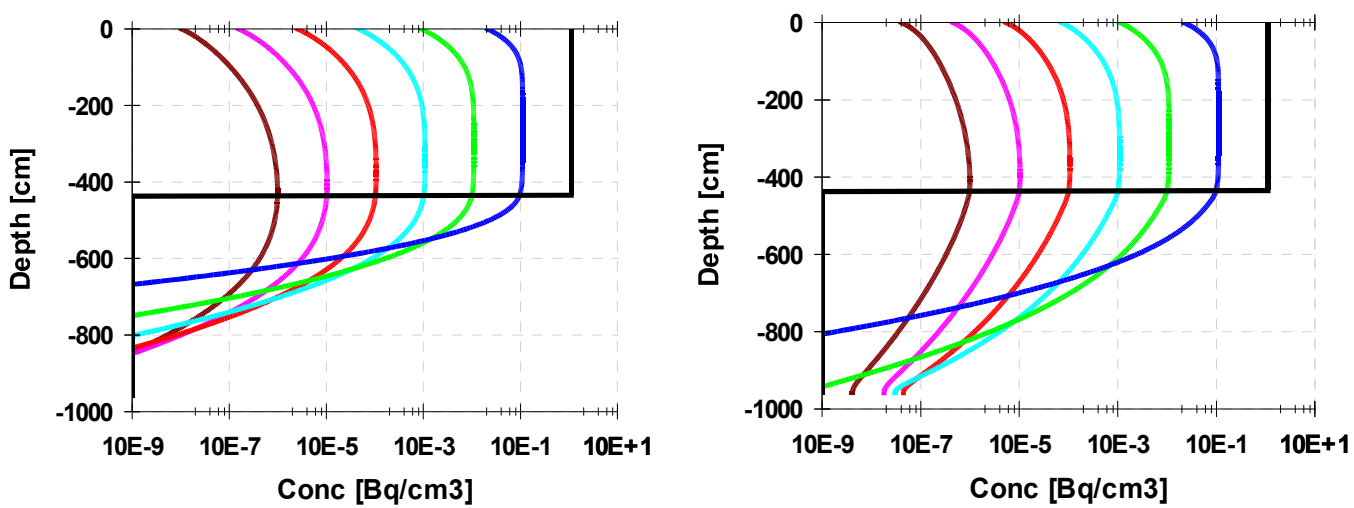

Fig. 11. Mobile concentration distributions in the repository and underlying vadose zone obtained with the dual porosity model using the parameters listed in Table 3 for Case A (left plot) and Case B (right plot). Distributions are given every 100 years from right $(t=0$, representing the initial condition) to left $(t=600$ years).

Table 3. Dual-porosity model parameter values used for the simulation in Figure 10.

\begin{tabular}{|c|c|c|c|c|c|c|c|}
\hline \multirow{2}{*}{ Layer } & \multirow{2}{*}{$\begin{array}{c}\text { Depth below upper } \\
\text { concrete liner (m) }\end{array}$} & \multicolumn{3}{|c|}{ Case A } & \multicolumn{4}{|c|}{ Case B } \\
\cline { 5 - 9 } & & $\theta_{i m}$ & $\begin{array}{c}f \\
(-)\end{array}$ & $\begin{array}{c}\alpha_{s} \\
\left(\text { year }^{-1}\right)\end{array}$ & $\begin{array}{c}\theta_{i m} \\
(-)\end{array}$ & $\begin{array}{c}f \\
(-)\end{array}$ & $\begin{array}{c}\alpha_{s} \\
\left(\text { year }^{-1}\right)\end{array}$ \\
\hline \hline Waste layer & $0-4.38$ & 0.20 & 0.20 & 0.01 & 0.20 & 0.20 & 0.1 \\
\hline Lower concrete liner & $4.38-4.58$ & 0.20 & 0.50 & 0.1 & 0.20 & 0.20 & 1.0 \\
\hline Vadose zone & $4.58-9.58$ & 0.20 & 0.50 & 0.1 & 0.20 & 0.20 & 1.0 \\
\hline
\end{tabular}

For the second scenario we superimposed on the first scenario the effects of possible preferential flow in both the waste layer and vadose zone. This since the waste layer was very heterogeneous by containing separate drums with the ${ }^{137} \mathrm{Cs}$ contaminated material, which likely caused infiltrating water to bypass much of the radioactive waste. Preferential transport was simulated using a mobile-immobile type dual-porosity model of the form (van Genuchten and Wagenet, 1989)

$$
\begin{aligned}
& \frac{\partial \beta \theta R C_{m}}{\partial t}= \\
& \frac{\partial}{\partial x}\left(\theta_{m} D_{m} \frac{\partial C_{m}}{\partial z}\right)-\frac{\partial q c_{m}}{\partial z}-\alpha_{s}\left(c_{m}-c_{i m}\right)-\beta \theta R \mu C_{m} \\
& \frac{\partial(1-\beta) \theta R C_{i m}}{\partial t}=\alpha_{s}\left(c_{m}-c_{i m}\right)-(1-\beta) \theta R \mu C_{i m}
\end{aligned}
$$

in which

$$
\beta=\frac{\theta_{m}+f \rho_{b} K_{d}}{\theta+\rho_{b} K_{d}}
$$

where the subscripts $m$ and $i m$ refer to the mobile and immobile regions of the soil (or concrete) such that $\theta_{m}+\theta_{i m}=\theta, f$ is the fraction of ${ }^{137} \mathrm{Cs}$ sorption sites located in the mobile region, and $\alpha_{s}$ is a first-order mass transfer coefficient governing the rate of solute exchange between the mobile and immobile liquid regions.

Figure 11 gives two plots based on dual-porosity simulations using the parameters listed in Table 3. For $\theta_{i m}$ we selected a reasonably large (and hence conservative) value that always remained below the minimum water contents in the three layers. The value of $f$ similarly is a fairly conservative value sug- gesting that $80 \%$ of the sorption sites are not in direct contact with the moving fluid. This again appears very reasonable for the heterogeneous waste material where water likely will bypass the containers filled with contaminated material. Finally, two values for the mass transfer coefficient $\alpha_{s}$ were used to cover relatively fast and slow solute exchange between the mobile and immobile liquid domains (Cases A and B in Fig. 11), based in part by an inventory by Maraqa (2001) of previously published values. The lower value of $\alpha_{s}$ for the waste layer (as compared to the vadose zone) was again motivated by the likely imperfect contact between the waste and presumed preferential fluid paths through the repository.

The results in Fig. 11 indicate that preferential flow in certain situations will lead to faster movement of the concentration front through the vadose one, and hence earlier breakthrough at the water table. However, the concentrations, as obtained especially for Case B in Fig. 11, are extremely low and well below the detection limit for ${ }^{137} \mathrm{Cs}$. Also, interestingly, is the effect of preferential flow in the waste layer as predicated by the selected values of $f$ and $\alpha_{s}$, leading to considerable bypassing of the waste. Preferential flow in that layer causes less rapid transport of ${ }^{137} \mathrm{Cs}$ out of the contaminated waste, and hence less pollution of underlying layers. These results are consistent with an earlier study (Pontedeiro et al., 2010) showing that preferential flow through a mining waste disposal site will lead to less rapid pollution of the subsurface by considerably lowering the concentrations leaving the disposal site. This is in contrast to situations where contaminated water originates at the soil surface, for example through some industrial accident or as part of agricultural practices such as the surface application of pesticides, in which case preferential flow will lead to more rapid downward transport and contamination of the vadose zone and underlying groundwater (e.g., Jarvis et al. 2016; Mallants et al., 2011). 


\section{CONCLUSIONS}

Decontamination of areas affected by the Goiânia radiation accident produced about $3,500 \mathrm{~m}^{3}$ of solid radioactive wastes, which were disposed of in two near-surface low-level repositories built in concrete in 1995 . In this paper we presented an analysis over a time period of 600 years of the repository containing the higher ${ }^{137} \mathrm{Cs}$ levels. Using HYDRUS-1D, we first obtained estimates of water infiltrating through the soil cover on top of the repository into and through the waste and its concrete liners and the underlying vadose zone towards groundwater. For the calculations we used atmospheric boundary conditions accounting for local precipitation and evapotranspiration rates, including root water uptake by the grass cover. Special concern was possible degradation of the concreate liners on top and below the waste material. We used HYDRUS-1D next to simulate long-term water fluxes and ${ }^{137} \mathrm{Cs}$ transport from the repository towards groundwater, thus providing an assessment of potential consequences to the environment and long-term exposure to the public. Results indicate that very little if any radioactive material will reach the water table during the lifespan of the repository.

Complete failure of the concrete liners from the very beginning also would not lead to any significant ${ }^{137} \mathrm{Cs}$ movement to groundwater below the repository. We note that recent tests (in 2017) revealed no noticeable degradation of the concrete liners, thus indicating that the adopted approach with concrete degradation was a very conservative scenario that may well have overestimated actual flow rates through the repository. Additional simulations assuming preferential flow caused faster transport to the groundwater table, but at concentrations far below the detection limit. In all, the current study confirms previous assessments by the Brazilian Nuclear Energy Commission (Heibron et al., 1996, 2002) that it is very unlikely to find in the future any unsafe concentrations of ${ }^{137} \mathrm{Cs}$ in the aquifer for populations living near the site.

\section{REFERENCES}

Aguiar, L.A., 2006. Avaliação de Risco de um Repositório Próximo à Superfície na Fase Pós - Fechamento em Cenários de Liberação de Radionuclídeos por Infiltração de Água. DSc Thesis, Department of Nuclear Engineering, COPPE, Federal University of Rio de Janeiro, UFRJ, Rio de Janeiro, Brazil, http://antigo.nuclear.ufrj.br/DScTeses/Lais/ tese_doutorado_lais.pdf (In Portuguese.)

Batalha, M.S., Bezerra, C.R., Pontedeiro, E.M., van Genuchten, M.Th., 2010. Environmental fate of natural radioactive contaminants in fertilizers and phosphogypsum. In: Proc. ENCIT 2010, $13^{\text {th }}$ Brazilian Congress of Thermal Sciences and Engineering, Dec. 5-10, 2010, Uberlandia, MG, Brazilian Soc. Mech. Sci. \& Eng., ABCM, Brazil.

Feddes, R.A., Kowalik, P.J., Zaradny, H., 1978. Simulation of Field Water Use and Crop Yield. John Wiley \& Sons, New York, NY.

Hargreaves, G.H., 1975. Moisture availability and crop production. Trans. Am. Soc. Agric. Eng., 18, 5, 980-984.

Heilbron, P.F.L, Tranjan Filho, A., Xavier, A.M., 1995. Safety Analysis Report (SAR) of the Concrete Waste Container (CGP). Internal Report. Brazilian Nuclear Energy Commission (CNEN), Rio de Janeiro, Brazil.

Heilbron, P.F.L., Rochedo, E., Xavier, A.M., 1996. Preliminary safety assessment of the first Brazilian repository. In: Proc. Int. Symp. Experience in the Planning and Operation of Low Level Waste Disposal Facilities. Int. Atomic Energy Agency
(IAEA), Vienna, 17-21 June 1996, IAEA-SM-341/8, pp. 395-404.

Heilbron, P.F.L, Pontedeiro, E.M., Cotta, R.M., PérezGuerrero, J., Ruperti, N.J., 2002. Reassessment of the safety of the Goiânia repositories. Internal Report. Brazilian Nuclear Energy Commission (CNEN), Rio de Janeiro, Brazil, http://www.cren-co.cnen.gov.br/documentos/anaseg-repo-1995-2002.pdf.

IAEA, 1988. The Radiological Accident in Goiânia. Int. Atomic Energy Agency (IAEA), Vienna, Austria, STI/PUB/815, $\quad 152 \quad 1$ p. $\quad$ http://wwwpub.iaea.org/mtcd/publications/pdf/ pub815_web.pdf.

Jacques, D., Maes, N., Perko, J., Seetharam, S.C., Phung, Q.T., Patel, R., Soto, A., Liu, S., Wang, L., De Schutter, G., Ye, G., van Breugel, K., 2013. Concrete in engineered barriers for radioactive waste disposal facilities - Phenomenological study and assessment of long term performance. In: Proc. ASME 2013 15th International Conference on Environmental Remediation and Radioactive Waste Management, pp. 1-10.

Jacques, D., Perko, J., Seetharam, S.C., Mallants, D., 2014. A cement degradation model for evaluating the evolution of retardation factors in radionuclide leaching models. Applied Geochemistry, 49, 143-158.

Jarvis, N., Koestel, J., Larsbo, M., 2016. Understanding preferential flow in the vadose zone: Recent advances and future prospects. Vadose Zone J., 15, 12. DOI: 10.2136/vzj2016.09.0075.

Mallants, D., van Genuchten, M.Th., Šimůnek, J., Jacques, D., Seetharam, S., 2011. Leaching of contaminants to groundwater. In: Swartjes, F.A. (Ed.): Dealing with Contaminated Sites; from Theory to Practical Application. Chapter 18. Springer Verlag, Dordrecht, The Netherlands, pp. 787-850.

Maraqa, M.A., 2001. Prediction of mass-transfer coefficient for solute transport in porous media. J. Contam. Hydrol., 53, 153-171.

Millington, R.J., Quirk, J.M., 1961. Permeability of porous solids. Trans. Faraday Soc., 57, 1200-1207.

Naveira-Cotta, C.P., Pontedeiro, E.M., Cotta, R.M., Su, J., van Genuchten, M.Th., 2013. Environmental impact assessment of liquid waste ponds in uranium milling installations. Waste Biomass Valor., 4, 197-211. DOI: 10.1007/s12649-0129156-0.

Pabalan, R.T., Glasser, F.P., Pickett, D.A., Walter, G.R., Biswas, S., Juckett, M.R., Sabido, L.M., Myers, J.L., 2009. Review of literature and assessment of factors relevant to performance of grouted systems for radioactive waste disposal. CNWRA 2009-001. Center for Nuclear Waste Regulatory Analyses (CNWRA), San Antonio, Texas.

Pashoa, A.S., Tranjan Filho, A., Rosenthal, J.J., 1993. Revisiting Goiânia: Toward a final repository for radioactive waste. Topical Report. IAEA Bulletin 1/1993, pp. 28-31.

Pontedeiro, E.M., van Genuchten, M.Th., Cotta, R.M., Šimůnek, J., 2010. The effects of preferential flow and soil texture on risk assessments of a NORM waste disposal site. J. Hazard. Mater., 174, 648-655. DOI: 10.1016/j.jhazmat.2009.09.100.

Pereira, J.C.A., 1996. Determinação da Velocidade de Migração e das Razões de Partição de 137Cs em Solos da Região do Futuro Repositório de Rejeitos de Abadia de Goiás, Goiás. MS. Thesis, Departamento de Química, Pontifícia Universidade Católica do Rio de Janeiro, Brazil. (In Portuguese.) 
Roberts, L., 1987. Radiation accident grips Goiânia. Science, 238, 4830, 1028-1031. DOI: 10.1126/science.3685964.

Robinson, B.A., Chu, S., Lu, Z., 2012. Simulation of radionuclide transport through unsaturated fractured rock: Application to Yucca Mountain, Nevada. Vadose Zone J., 11, 4. DOI: $10.2136 /$ vzj2011.0142

Schneider, S., Jacques, D., Mallants, D., 2012. Estimating unsaturated hydraulic properties of concrete C-15-A and mortar M1. Mater. Res. Soc. Symp. Proc., Vol. 1475. DOI: 10.1557/opl.2012.601.

Šimůnek, J., van Genuchten, M.Th., Šejna, M., 2016. Recent developments and applications of the HYDRUS computer software packages. Vadose Zone J., 15. DOI: 10.2136/vzj2016.04.0033.

Tsang, C.-F. (Ed.), 1987. Coupled Processes Associated with Nuclear Waste Repositories. Academic Press, London, UK. van Genuchten, M.Th., 1980. A closed-form equation for predicting the hydraulic conductivity of unsaturated soils. Soil Sci. Soc. Am. J., 44, 5, 892-898.

van Genuchten, M.Th., Wagenet, R.J., 1989. Two-site/two-region models for pesticide transport and degradation: Theoretical development and analytical solutions. Soil Sci. Soc. Am. J., 53, 5, 1303-1310.

Yu, C., Gnanapragasam, E., Biwer, B.M., Kamboi, S., Cheng, J.-J., Yuan, Klett, T., LePoire, D., Ziele, A.J., Chen, S.Y., Williams, W.A., Wallo, A., Domotor, S., Mo, T., Schwartzman, A., 2007. User's manual for RESRADOFFSITE. Version 2. ANL/EVS/TM/07-1. Argonne National Laboratory, Argonne, IL.

Received 9 May 2017 Accepted 31 August 2017

Note: Colour version of Figures can be found in the web version of this article. 